\title{
Management of Personal Information among Library Staff at the University of Dar es Salaam, Tanzania
}

\author{
Emmanuel Mkhai \\ Information Studies Programme, University of Dar es Salaam, Tanzania \\ Email: memaemmanuel@yahoo.com \\ Nakivona Hashim Rashid \\ Tanzania Public Service College \\ Email: nakie.hashim@gmail.com
}

\begin{abstract}
Effective management of personal information is pivotal for its sustainable use. This article presents a study that has assessed the personal information management (PIM) practices of library staff at the University of Dar es Salaam (UDSM). The study used a descriptive research design deploying both qualitative and quantitative approaches under which questionnaire and focus group discussion guide were used to collect data. While qualitative data were subjected to content analysis, statistical analysis was used to generate descriptive and inferential statistics from quantitative data using IBM SPSS version 23. The findings have revealed that librarians at are generally aware of various PIM practices and use them to manage their personal information. The librarians use both physical and electronic tools to manage their personal information. These tools include physical folders, files, and boxes, which are used to manage physical information, and Dropbox, Google Drive, and iCloud which are used to manage electronic information. Several factors influence the effectiveness of librarians' PIM practices. These include librarians' demographic characteristics (age and levels of education), knowledge of the information cycle, information management skills, and available information systems. Factors such as inadequate information management skills and shortage of time have been found to undermine the effectiveness of the studied population's PIM practices. The study concludes that understanding factors that influence and undermine effective PIM practices is essential in setting a foundation for improving personal information management.
\end{abstract}

Keywords: Personal information management, library staff, information management, information professionals, knowledge management

https://dx.doi.org/10.4314/udslj.v16i2.12

\section{Introduction}

Personal information management (PIM) is not a new practice since it appears to have been embraced by human race since ancient ages (Jones \& Teevan, 2007). Generally, the practice involves the acquisition, organisation, maintenance, retrieval, use and control of different information resources (Jones, 2007; Bergman et. al., 2004). PIM ensures the availability of information at the right time. As such, this practice is fundamental in people's informed decisions making and accomplishment of goals (Hajibayova, 2019; Bergman, 2013; Bergman et al., 2004). This aside, PIM is advantageous in many ways, including: time saving in information retrieval, easing information retrieval through proper arrangement, enabling effective and efficient 
accomplishment of tasks, prevention of information overload as well as enhancing accessibility to information. All these are essential to people's personal and professional lives (Sawant \& Manchekar, 2019). Practically, when a person creates or receives information, the likelihood is that there will be a need for it in the future; thus calling for its proper management to maintain its authenticity (Diekema \& Olsen, 2011). In other words, everyone, including and more especially information professionals, needs to have a particular way of managing all the information they produce, receive or own (Lush, 2014). By virtue of their line of work, information professionals, in this case, library staff are expected to effectively manage their personal information so as to be able to optimally exploit it (Fourie, 2012). Like for anyone else, information professionals' information and knowledge requirements are growing; resulting in demands for more effective management of personal information (Hwang et al., 2015).

To enhance the effectiveness of PIM, numerous initiatives have been made by different stakeholders globally. The initiatives include the introduction of various physical and electronic personal information management systems. Tools such as box files, personal handbooks, cabinets, flat files, and cupboards are some of the physical systems used to manage personal information (Pikas, 2007). Aside from these, a variety of personal information management software and hardware are available. Interest in electronic PIM systems has grown along the rapid proliferation of microcomputers since the 1980s. For example, notebook computers and pen-based input devices are perfect for supporting PIM. Along these, various personal information management software and hardware such as Phlat, MemoMail, Photomemory, and MyLifeBits (Al Nasar et al., 2011) have been developed to support people's management of their personal information.

Surprisingly, despite the known importance PIM has as evident in continued development of its systems, loss and destruction of personal information remain critical problems. Evidence from previous studies (Bergman \& Whittaker, 2017) indicates that there is lack of evidence towards ownership of various personal documents and failure to promptly retrieve information when required to facilitate the surrounding needs and decision making. As a consequence, people continue to fail to provide original copies of their personal documents such as academic certificates; a state that puts into question how such information resources are managed. For Tanzania, there are some notable indications of poor management of personal information. A practical example is what happened in 2017 when the Tanzanian government laid off many people from civil service, including library staff. Although majority of the permanent layoffs were due to submission of forged documents, a good number of people were casualties of failure to submit documents, generally because they had lost them. It is due to this background that this study aimed at assessing factors contributing to effective management of personal information by library staff at the University of Dar es Salaam. Specifically, the study sought to answer the following questions:

RQ1: What are the personal information management practices known among UDSM library staff members?

RQ2: What are the factors associated with effective management of personal information among library staff at UDSM?

\section{Related Literature}

Management of Personal Information among Library Staff at the University of Dar es Salaam, Tanzania 
Personal information management entails all activities related to the creation/ receipt, storage, maintenance, usage, retrieval, and distribution of personal information (Kearns et al., 2014) In line with the provided definition, Majid et al. (2010) explain that the management of personal information starts with its creation to give it power to exist prior to other considerations being made. Lush (2014) adds that after being acquired, personal information must be organized properly to ensure all the information is kept in the right places to facilitate retrieval. For instance, saving personal information in various formats is not only done for retrieval purposes, but also to sustain the information's availability (long term preservation) for use when needed (State of Archives of North Carolina, 2012).

With respect to sustaining the existence of personal information, authors (Kearns et al., 2014; Jones, 2007) argue that information creation tools and systems should be used with information sustainability in mind. There are various physical and electronic tools used to manage personal information depending on the nature of the information available - print or electronic. Physical tools that are mostly used to manage personal information include flat and box files, personal handbooks, cabinets, and cupboards (Pikas, 2007). On the other hand, electronic information management tools used in personal information management include external hard drives, citation management tools (mendeley, zotero, endnote, evernote), cloud computing tools (Dropbox, Google Drive, XMarks), content alerts, RSS feed tools (content alerts, database alerts) and emails (Connel, 2011; Prasad, 2016). Both physical and electronic information management tools are regarded by Opuku (2015) as an important concern for effective management of personal information that library staff have to bear in mind.

It is acknowledged that no factor can single-handedly ensure effective management of personal information. In fact, there is an interaction between how and where personal information is created or received, captured and arranged, stored and maintained, and effective management of personal information (Runardotter et al., 2006). As presented by Fourie (2012), awareness of personal information management practices has a positive impact on the application of related skills for the same purpose (Hajibayova, 2019). Specifically, awareness of personal information management practices is said to be the base of effective management of personal information because it gives way for the integration related skills for that effect. Library staff's awareness of personal information management has been found by Creegan (2017) to emanating from their professional activities. Since dealing with information management is their core professional responsibility, it is easy for these individuals be aware of other information management practices.

Other studies, such as that by Bessick (2016), have identified that information management dynamics; the cycle of information, information management strategies, and change in policies determine how effectively personal information is managed. Furthermore, Hajibayova (2019) identified that the age of an information owner influences their management of personal information. According to Kearns et al. (2014) information quantity is another influential factor in effective management of personal information. Apart from quantity, it is argued that as the worth of information increases, demand for attention increases too, such that if one is not attentive enough, the possibility of losing valuable information is bigger (Kearns et al.., 2014). In a way, this factor predicts the education level and types or quality of systems needed to manage personal information; which are both important factors that determine effective management of personal information (Almutairi, 2011).

Various challenges have been linked to people's failure to manage personal information. Prior studies (Radovic-Markovic \& Vucekovic, 2015; Fourie, 2012) have associated lack of personal information management skills and knowledge with poor management of such information. 
According to the studies, this challenge sometimes results in the same piece of information, in the same format, being stored under different names (labels), making its retrieval difficult. Furthermore, other studies (e.g., Hoq, 2014) have found that information owners lack time to process and interact with multiple sources of information hence having difficulties with organizing and processing information. Additionally, management of personal information is challenged by information fragmentation, which is most common in electronic information, especially when different applications are used to open a particular piece of information on various devices (Connell, 2011). This practice might cause changes in the directory of information hence affecting future retrieval activities. Apart from these challenges there is one to do with balancing between privacy and preservation of information. While managing personal information in manual systems ensures high privacy, the systems are less capable of ensuring the longevity of information; which is the direct opposite of what one should expect with electronic systems (Majid et al., 2010). Nonetheless, that is an unavoidable complexity that people must navigate to ensure total security of their information.

\section{Conceptual Framework}

The conceptual framework presented hereunder has been used to guide this study. The framework indicates the association between personal information management activities and various factors that work for or against its effectiveness. On the framework, independent variables comprise creation, organization, processing, and maintenance of personal information. The capabilities required to ensure effective management of personal information include age, education, information management skills, information cycle and administrative systems.

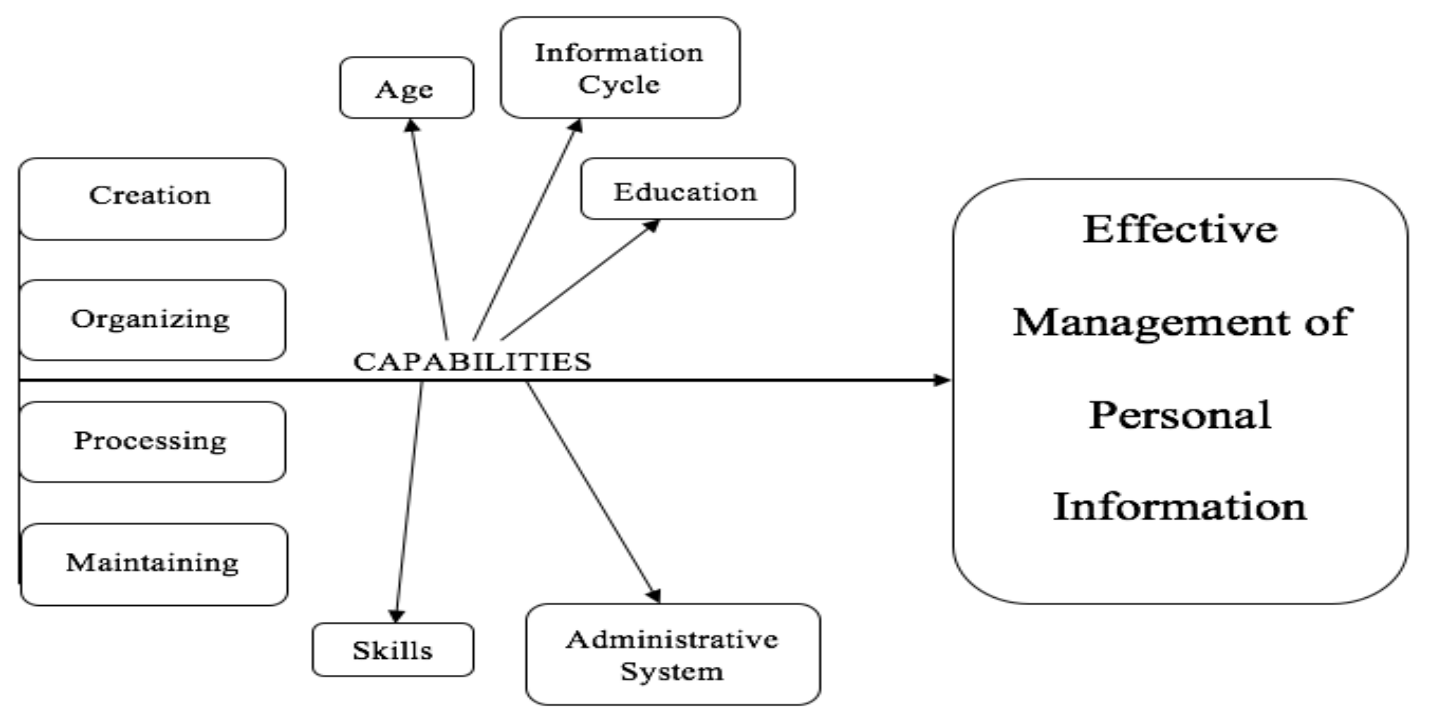

Figure 1: Conceptual Framework

\section{Source: Modified from Sub Dimensions of Personal Information Management Effectiveness}

Based on the framework, for effective management of personal information to be possible, library staff must be knowledgeable about the information's creation, organization, processing, and Management of Personal Information among Library Staff at the University of Dar es Salaam, Tanzania 
maintenance. With regards to creation, one needs to be able to sense/identify personal information and collect it whether they have created it themselves or received from another person, institution, agency or body, as far as it concerns the person in question. The handling of the collected information is believed to rely on the age, management system used, education level, information cycle, and information management skills of the concerned individual. The nature of the combination of these factors will determine how effectively the information will be managed. For instance, younger individuals might manage personal information differently if compared to older ones. This also applies to differences in education and skills. Similarly, the management system that an individual uses to manage personal information might have an influence on how the information managed.

\section{Material and methods}

This study used a descriptive research design employing a mixed methods approach for the purpose of describing factors that influence effective management of personal information. The study was conducted at the University of Dar es Salaam involving library staff (librarians and library staff involved in teaching) from the University Library; who were included in the study through census method; meaning all (146) library staff, both academic and administrative were part of the study. However, only $116(80 \%)$ of these successfully participated in the study. Questionnaire method (using a semi structured questionnaire) and Focus Group Discussions (FGDs) method were used to collect data from the respondents. Two FGD sessions involving 7 participants each were held. The participants in the FGDs were purposively selected based on their level understanding about the topic in question and their ability to express themselves when in group. Content analysis was used to analyze qualitative data while descriptive and inferential statistics were generated from quantitative data with the help of IBM Statistical Product and Service Solutions (SPSS) version 23. Analysis outputs have been presented in form of quotations, tables, and figures as will be seen in the next section.

\section{Study results}

\section{Demographic characteristics of respondents}

Overall, the study involved a total of 116 respondents. Results, as demonstrated in Table 1, show that a substantial number of the respondents were aged between 20 and 40 years. On the other hand, very few respondents $(1.7 \%)$ were aged 60 and above. Education wise, the findings show that the respondents were of different levels of education ranging from certificate to $\mathrm{PhD}$ level. Specifically, nearly one-third (32.8\%) of the respondents had diplomas, a handful $(9.5 \%)$ had $\mathrm{PhDs}$ and very few $(5.2 \%)$ had certificates. Table 1 shades more light on this.

Table 1: Demographic characteristics of respondents

\begin{tabular}{|c|c|c|}
\hline Category & Frequency & Percentage \\
\hline Age & & \\
\hline $20-30$ & 44 & 37.9 \\
\hline $31-40$ & 37 & 31.9 \\
\hline $41-50$ & 18 & 15.5 \\
\hline $51-60$ & 15 & 12.9 \\
\hline 60 and above & 2 & 1.7 \\
\hline
\end{tabular}




\begin{tabular}{lcc} 
Education & & \\
PhD & 11 & 9.5 \\
Masters & 22 & 19 \\
Bachelor degree & 29 & 25 \\
Postgraduate diploma & 10 & 8.6 \\
Diploma & 38 & 32.8 \\
Certificate & 6 & 5.2 \\
\hline
\end{tabular}

\section{Source: Field Data, 2020}

\section{Personal information management practices known by library staff}

Respondents were asked to rate their levels of awareness of different PIM practices. A Likert scale using very high, high, moderate, low, and very low was used for this purpose. Results, as illustrated by Figure 2, show that the majority (83.7\%) of the respondents were highly aware of various PIM practices while very few $(0.9 \%)$ indicated that they were inadequately aware of the practices.

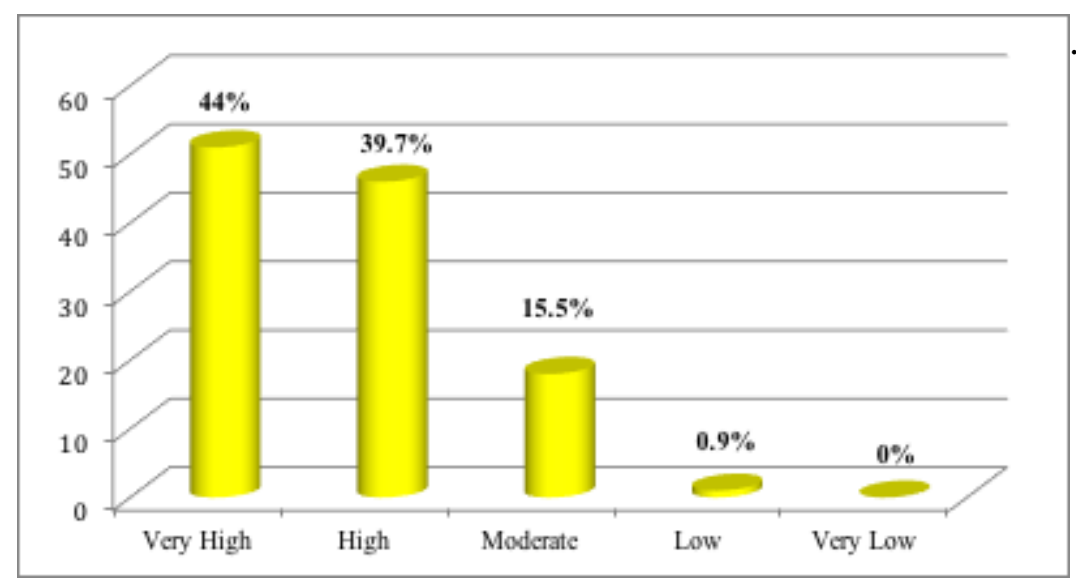

Figure 2: Awareness of PIM practices Source: Field Data, 2020

To further assess the respondents' awareness of various PIM practices, an open-ended question requiring respondents to mention different PIM practices they knew and used to manage their personal information was asked. Several PIM practices were mentioned, including how personal information is generated, its purpose, how it is organized, and the need for saving it in various formats to enhance its long term preservation and the need for its quick and efficient retrieval.

The respondents also mentioned the tools they used to manage personal information. These included personal computers and smartphones, and physical tools such as folders, boxes, and cabinets. Other respondents mentioned that they also use cloud storage facilities such as Dropbox, Google Drive, and iCloud to manage their personal information. These findings corroborate those from FGDs where participants mentioned almost the same practices as illustrated in the following quotations:

I normally use email for various information organization purposes, whereby I organize my mails' folders through filters. I have two email accounts, one for Management of Personal Information among Library Staff at the University of Dar es Salaam, Tanzania 
personal stuff and the other for work related activities. I usually mark important emails and those that need urgent response using a "star" mark for effective response.

I have my personal physical files at home which I use to keep my personal information. These files are put in a secured area at my home and some of the copies of my personal information are in the other physical files stored in the file cabinets in my office to ensure easy access to my personal information.

Google drive has been my common cloud storage application for managing my personal information because it is linked to my email address. It provides a huge initial free storage capacity (about $15 \mathrm{~GB}$ ) and it is interactive in its application such that I don't lose my personal information because of the automatic backup.

These quotations, apart from showing that the study respondents were aware of different PIM practices, show that the respondents use the same practices to manage their personal information. In addition, the results suggest a possibility of the respondents' adoption of a blended or hybrid approach to managing their personal information. This possibility is evident in the tools (electronic and physical) that seemed to be serving PIM purposes at the time of data collection.

\section{Sources of PIM knowledge}

Respondents were asked to indicate how they got their PIM practices knowledge. The results indicated in Table 2 show that a significant number of them got their knowledge of these practices through training, seminars, and workshops. The results further reveal that the majority of the respondents also obtained this knowledge through their personal practices and experiences. More than half $(62.9 \%)$ of the respondents indicated that they use the Internet to get information about PIM practices. See Table 2 for more details.

Table 2: Sources of knowledge of PIM among respondents

\begin{tabular}{lcc}
\hline \multicolumn{1}{c}{ Source } & Frequency & Percentage \\
Training, Seminars and Workshops & 99 & 85.3 \\
Personal Practices & 83 & 71.6 \\
Experience & 79 & 68.1 \\
Internet & 73 & 62.9 \\
\hline
\end{tabular}

Source: Field Data, 2020

Factors that influence effectiveness in library staff's management of personal information Factors influencing effective management of personal information management were the other variable of interest to this study. Based on the conceptual framework of this study, three factors that are believed to influence effective PIM were assessed. These factors are information cycle, information management skills, and information systems available for the management of personal information. A three-level Likert scale using agree, undecided, and disagree was used for this purpose (see Table 3). 
Table 3: Factors influencing effective management of personal information

\begin{tabular}{lccc}
\hline \multicolumn{1}{c}{ Factors } & Agree & Undecided & Disagree \\
Information cycle & $101(87.1)$ & $13(11.2 \%$ & $2(1.7 \%)$ \\
Information management skills & $71(61.2 \%)$ & $16(13.8 \%)$ & $29(25 \%)$ \\
Available administrative system & $92(79.3 \%)$ & $18(15.5 \%)$ & $6(5.2 \%)$ \\
\hline
\end{tabular}

\section{Source: Field Data, 2020}

Results, as indicated in Table 3, show that the majority of respondents agreed that all the three mentioned factors are responsible for the effective management of their personal information. In contrast, a quarter (25\%) of the respondents said that one of the three mentioned factors (information management skills) did not affect how effectively they manage their personal information.

To further assess the factors' influence on PIM, a Chi-square test was used. Five variables including two demographic characteristics of respondents, namely; respondents' age and their level of education, and the other three variables, namely; information cycle, information management skills, and administrative system were tested and Table 4 shows the results of the test.

Table 4: Association between selected variables and effective management of PIM

\begin{tabular}{lcc}
\hline Variable & Effective management of personal information \\
& Value & $P$ \\
Age & 9.820 & 0.044 \\
Education & 11.568 & 0.041 \\
Information cycle & 60.017 & 0.000 \\
Information management skills & 11.512 & 0.021 \\
Administrative system & 32.7641 & 0.008 \\
\hline
\end{tabular}

Source: Field Data, 2020

The results in Table 4 indicate that the associations of respondents' age, level of education, information cycle, information management skills, and available information systems are statistically significant at 5\% or less. This implies that these variables are the primary determinants of effective management of personal information among members of the studied population. Specifically, these findings, particularly those on information cycle, information management skills, and information system confirm the ones presented in Table 3.

\section{Factors undermining effective management of personal information}

Respondents in this study were asked to indicate factors that undermine effective management of their personal information. A five-point Likert scale using Strongly Agree (SA), Agree (A), Neutral (N), Disagree (D), and Strongly (SD) was employed for this purpose. Table 5 summarizes the responses received on this.

Table 5: Factors undermining effective management of personal information

\begin{tabular}{llllll} 
Undermining Factors & SA & A & N & D & SD \\
\hline
\end{tabular}

Management of Personal Information among Library Staff at the University of Dar es Salaam, Tanzania 


\begin{tabular}{|c|c|c|c|c|c|}
\hline $\begin{array}{l}\text { Inadequate Skills for } \\
\text { Managing Personal } \\
\text { Information }\end{array}$ & $63(54.3 \%)$ & $46(39.7 \%)$ & $6(5.2 \%)$ & $1(0.9 \%)$ & 0 \\
\hline $\begin{array}{l}\text { Shortage of Time for the } \\
\text { Management of PI }\end{array}$ & $37(31.9 \%)$ & $48(41.4 \%)$ & $25(21.6 \%)$ & $3(2.6 \%)$ & $3(2.6 \%)$ \\
\hline Information overload & $33(28.4 \%)$ & $56(48.3 \%)$ & $23(19.8 \%)$ & $4(3.4 \%)$ & 0 \\
\hline $\begin{array}{l}\text { Inability to Access } \\
\text { Multiple Sources of } \\
\text { Information }\end{array}$ & $40(34.5 \%)$ & $49(42.2 \%)$ & $20(17.2 \%)$ & $7(6 \%)$ & 0 \\
\hline $\begin{array}{l}\text { Inflexibility of } \\
\text { Information File Formats }\end{array}$ & $39(33.6 \%)$ & $48(41.4 \%)$ & $22(19 \%)$ & $6(5.2 \%)$ & $1(0.9 \%)$ \\
\hline $\begin{array}{l}\text { Use of Inappropriate } \\
\text { Tools }\end{array}$ & $50(43.1 \%)$ & $53(45.7 \%)$ & $9(7.8 \%)$ & $3(2.5 \%)$ & $1(0.9 \%)$ \\
\hline
\end{tabular}

\section{Source: Field Data, 2020}

Overall, results from Table 5 suggest that there are a multitude of factors that undermine effective management of personal information. Specifically, nearly all study respondents (94\%) indicated that they were inadequately skilled to manage their personal information. Nearly three-quarters (73.3\%) of the respondents also identified shortage of time as another factor that undermine effective management of their personal information. A substantial number of respondents also mentioned format-inflexibility resulting from technological changes in the tools used to manage personal information as a challenge to them. This challenge was also noted in one of the FGD sessions where one participant stated that:

File formats inability to match the change in technology affects effective management of personal information. Most of formats do not have the capacity to migrate data therefore impossible to access such information using other formats.

This finding as indicated both in the table and the quotation signify that the majority of the study respondents had inadequate knowledge on how to manage their personal information. In the real sense, format is not supposed to be flexible. Technology is supposed to have that characteristic so to accommodate information in older formats when a system has been upgraded. This finding, therefore, show that a majority of the study respondents were not adequately aware of the appropriate technology to use to manage their personal information. Information overload, inability to access multiple sources of personal information, and use of inappropriate tools to manage personal information were also mentioned by a significant number of respondents as factors undermining effective management of their personal information.

\section{Discussion}

This study has assessed personal information management (PIM) practices of library staff at the University of Dar es Salaam. The study's findings have demonstrated that library staff at the University were aware of various PIM practices and used them to manage their personal information. These findings are in line with those from similar previous studies (Jones, 2012; Lush, 2014; Rapp \& Cena, 2016; Schmidt, 2020) which also observed that librarians and other information professionals are aware of how personal information is created, organized, and preserved for efficient retrieval. These findings, therefore, do not diverge from the general 
expectation that by virtue of their work, librarians are well positioned to be knowledgeable about PIM. Since the skills they need in their professional responsibilities are not that different from those demanded in PIM, it is understandable that the study has come up with these results.

To effectively manage personal information, various tools, both physical and electronic are used. This study has revealed that librarians at the University use different tools to manage their personal information. Whilst tools such as physical folders, files, boxes, and cabinets were used to manage physical information, cloud storage facilities such as Dropbox, Google Drive, and iCloud were used to manage electronic personal information. As also found by other studies such as ones by Prasad (2016) and Connel (2011), email is another tool commonly used by majority of library staff at the study are to manage personal information. However, it is not clear in this study as to whether the library staff use both physical and electronic tools concurrently or separately to manage their personal information. Concurrent use of these tools $\mathrm{f}$ is essential for sustainable management of personal information.

In terms of sources of PIM knowledge, the study has revealed that library staff were introduced to PIM practices through trainings, seminars, workshops, personal practices and experience, and through internet. In other words, how these individuals manage their information is a product of the just mentioned learning opportunities. Similar findings were reported by Hwang, Kettinger and Mun (2014) who noted the same sources of knowledge as fundamental in assisting people to effectively manage their personal information.

Several factors have been found to influence effective PIM practices among library staff at the University. This was confirmed by the statistically significant association found between demographic characteristics of respondents and effective PIM. According to the study, library staff's ages and levels of education, and other three variables, namely; information cycle, information management skills, and information systems have a strong association with effectiveness in PIM endeavours. This finding suggests that these variables are the main determinants of effective PIM practices. A significant association between age and effective PIM practices entails that individuals with younger ages manage their personal information more effectively than older ones. This finding confirms the conceptual framework used in this study which shows a linkage between age and effective PIM practices. The finding also confirms those from previous studies (e.g. Kezer, et. al., 2016) which associated age differences with effective management of personal information.

As noted by Gregory and Descubes (2011), information cycle is indispensable in effective PIM practices. It is important to note that the cycle starts when information is created organized, processed and maintained for a particular purpose. The significant association between information cycle and effective PIM practices confirms its importance in PIM. Similarly, a significant association between information management skills and PIM practices suggests that the former are pivotal for effective PIM practices. These skills, as observed by Radovic-Markovic and Vucekovic (2015), are engines behind effective management of personal information. Furthermore, the study has found that there is a direct relationship between information systems and effective PIM; suggesting that the type of system a library staff uses has an impact on their management of personal information.

In this study, various factors have been found to undermine respondents' effective management of personal information. While information management skills are considered essential (Radovic-Markovic \& Vucekovic 2015) for effective management of personal information, a substantial number of respondents in this study admitted to lack them. This suggests

Management of Personal Information among Library Staff at the University of Dar es Salaam, Tanzania 
that being information professional does not guarantee one to have adequate skills, more so because these skills need regular updating. Furthermore, the findings raise questions regarding the adequacy of the training offered to the studied population through the methods identified earlier. Shortage of time to manage personal information was another factor found to undermine effective management of personal information. This might be due to the fact that as librarians, the respondents are engaged in different work-related activities which might be taking most of their time. Similar to findings from past studies (Kearns et al.., 2014; Stewart, Basic \& Erdelez, 2012), this study has also revealed that information overload is a challenge to many people's PIM. However, it has to be noted that this problem usually result's from people's inability to effectively respond to the speed of information creation.

Aside from that, this study also reveals that inability to access multiple sources of information undermines the management of personal information among its respondents. This may lead a person to obtaining incorrect or incomplete information hence difficulties in its management. This can be attributed to lack of sufficient information management skills or time to access multiple sources of information. This finding, however, is not peculiar to this study only as prior studies (e.g., Montoya et al., 2018) have also reported it. It is also worth noting that technology is considered key in the management of personal information. However, consistent with findings from Cascio and Montealegre (2016), this study shows that inflexibility of information file formats due to technological changes undermines effective management of personal information. This hinders effective retrieval of information. Along that, the use of incorrect tools was also perceived to undermine effective management of personal information in this study. This problem suggests limited awareness of proper tools for managing personal information. Poor selection of tools for managing information negatively impacts the sustainability of information (Kearns et al., 2014; Jones, 2007).

While this study has shed light on the library staff' practices on PIM, it also has some limitations. It is worth noting that the significant association between education and effective PIM practices should be looked at with caution since this study involved a population that is generally trained to manage information. As such, there are chances that the relationship between these variables may not be the same as the one found by this study if other populations are used.

\section{Conclusion}

Effective management of personal information is pivotal for its sustainable use. Overall, the study sheds light on the different practices library staff engage in to managing their personal information. Furthermore, understanding the factors that influence effective management of personal information by the study respondents is essential in setting a foundation for improving personal information management. Factors such as age, education, information cycle, information management skills, and available information systems deserve attention as far as effective management of personal information is concerned. Despite demonstrating adequate awareness on various PIM practices and utilization of different physical and electronic tools to manage their personal information, library staff face different challenges that undermine effective PIM practices. This study recommends that more training and workshops relevant to the needs of the studied population should be provided to enhance their skills on management of their personal information. 


\section{References}

Almutairi, H. (2011). Factors affecting the information behavior of managers in the Kuwait civil service: A relational model. Information Research. 16(2), paper no. 447.

Al Nasar, M. R., Mohd, M., \& Ali, N. M. (2011). Information management systems and interfaces: An overview. International Conference on Semantic Technology and Information Retrieval. IEEE pp. 197 - 202.

Bergman, O., Boardman, R., Gwizdka, J., \& Jones, W. (2004). Personal Information management. Conference on Human Factors in Computing Systems - Proceedings, (December 2012), 1598-1599. https://doi.org/10.1145/985921.986164

Bergman, O. (2013), Variables for personal information management research. Aslib Proceedings, 65(5), pp. 464-483. https://doi.org/10.1108/AP-04-2013-0032

Bergman, O. \& Whittaker, S. (2017). The science of managing our digital stuff. London: MIT Press.

Bessick, J. R. (2016). Factors influencing effective Information Management using information technology systems in a Public Sector Department. PhD Thesis, University of Western Cape.

Cascio, W. F., \& Montealegre, R. (2016). How technology is changing work and organizations. Annual Review of Organizational Psychology and Organizational Behavior, 3, 349-375. https://doi.org/10.1146/annurev-orgpsych-041015-062352.

Creegan, T. D. (2017). A study of the personal information management practices of librarians. Masters' Thesis, Victoria University of Wellington.

Connell, A. (2011). Personal Information Management. Personal Information Management, 1334. https://doi.org/10.1007/978-1-4614-5308-6_12

Diekema, A. R., \& Olsen, M. W. (2011). Personal information management practices of teachers. Proceedings of the ASIST Annual Meeting, 48. https://doi.org/10.1002/meet.2011.14504801189

Fourie, I. (2012). Collaboration and personal information management (PIM). Library Hi Tech, 30(1), 186-193. https://doi.org/10.1108/07378831211213292

Gregory, M., \& Descubes, I. (2011). Understanding PIMS: Personal informatin management system. Research Journal of Economics, Business and ICT 3(1), 31-37.

Hajibayova, L. (2019). Exploring individuals' patterns of personal information management practices: Factors influencing the representation, organization and credibility assessment of information. Information Research, 24(3), paper 835. retrieved from http://InformationR.net/ir/24-3/paper835.html

Hoq, K. M. G. (2014). Information Overload: Causes, consequences and remedies - A study. Philosophy and Progress, 2278, 49-68. https://doi.org/10.3329/pp.v55i1-2.26390

Hwang, Y., Kettinger, W. J., \& Yi, M. Y. (2015). Personal information management effectiveness of knowledge workers: Conceptual development and empirical validation. European Journal of Information Systems, 24(6), 588-606. https://doi.org/10.1057/ejis.2014.24

Jones, W. (2012). The future of personal information management: Part 1: Our information, always, and forever. Systhesis Lectures on Information Concepts, Retrieval, and Services. 4(1), 1 - 125.

Jones, William P. \& Teevan, Jaime (2007). Personal information management. Seattle: University of Washington Press.

Management of Personal Information among Library Staff at the University of Dar es Salaam, Tanzania

Emmanuel Mkhai \& Nakivona Hashim Rashid 
Kearns, L. R., Frey, B. A., \& Alman, S. (2014). A study of personal information management strategies for online faculty. Journal of Asynchronous Learning Networks, 18(1). 1 - 17.

Kezer, M., Sevi, B., Cemalcilar, Z., \& Baruh. (2016). Age differences in privacy attitudes, literacy and privacy management on Facebook. Journal of Psychosocial Research on Cyberspace, 10(1), $1-21$.

Lush, A. (2014). Fundamental personal information management activities-organisation, finding and keeping: A literature review. Australian Library Journal, 63(1), 45-51.

Majid, S., San, M. M., Tun, S. T. N., \& Zar, T. (2010). Using Internet services for personal information management. In International Symposium on Information Management in a Changing World (pp. 110-119). Springer, Berlin, Heidelberg.

Montoya, D., Tanon, T.P., Abiteboul, S., Senellart, P., \& Suchanek, F.M. (2018). A knowledge base for personal information management. Paris: Lyon.

Opoku, Mustapha Osman (2015). Information management and organizational performance: A review of literature. Mediterranean Journal of Social Sciences, 6(1) 62 - 70.

Pikas, C. K. (2007). Personal information management strategies and practices used by senior engineers. Asis \&t. 44(1), 1 - 21.

Prasad, M. (2016). Personal information management tools to made your research easy. International Journal of Library and Information Studies, 6(1), 185 - 191.

Rapp, A., \& Cena, F. (2016). Personal informatics for everyday life: How users without prior selftracking experience engage with personal data. International Journal of Human Computer Studies, 94(10), 1-17. https://doi.org/10.1016/j.ijhcs.2016.05.006

Runardotter, M., Quisbert, H., Nilsson, J., Hägerfors, A., \& Mirijamdotter, A. (2006). The information life cycle: Issues in long-term digital preservation. Arkiv, Samhälle Och Forskning, 1, 17-29.

Sawant, S., \& Manchekar, B. (2019). Personal information management by Ph.D. scholars of library and information science in India. Library Philosophy and Practice (e-journal), paper no. $2927 \quad$ Retrieved from https://digitalcommons.unl.edu/cgi/viewcontent.cgi article $=6182 \&$ context=libphilprac

Schmidt, C. (2020). Document File Types - Important Updates and Differences. Canto. Retrieved from: https://www.canto.com/blog/document-file-types/ 